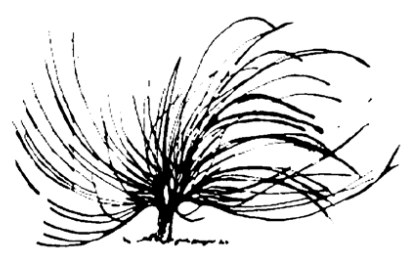

\title{
Entre o ver e o refletir: supressão da criança em relatórios de estágio de alfabetização
}

\author{
Tathiane Graziela Cipullo ${ }^{1}$ \\ Faculdade de Educação, Universidade de São Paulo \\ Brasil \\ tathiane.graziela@yahoo.com.br
}

\begin{abstract}
Resumo
O objetivo do presente artigo é discutir a formação dos professores destinados a trabalhar com a infância a partir da análise de relatórios de estágios de alfabetização. Partimos da premissa de que a escrita sobre a prática profissional é mais que simples documentação ou comprovação de atividades, mas um momento de reflexão e análise da prática que pode resultar em produção de conhecimento. Analisamos dez relatórios de estágio com o intuito de verificar em que medida os graduandos estabelecem a relação entre teoria e prática. Como resultado, observamos que o propósito maior do fazer pedagógico está suprimido dos relatos, ou seja, a criança pouco aparece e quando aparece é descrita, principalmente, como um ser faltante - que não aprendeu, não desenvolveu, não faz, que não atende as expectativas dos adultos. Tais dados nos levam a questionar como está se dando a atual formação do Pedagogo e por que seus estudos não reverberam na prática.
\end{abstract}

Palavras-chave: infância, formação de professores, alfabetização, relatórios de estágio.

http://dx.doi.org/10.15359/rep.esp-20-1.9

1 Formada em Letras pela Universidade de São Paulo, é professora dos Ensinos Fundamental II e Médio e mestranda da Faculdade de Educação da Universidade de São Paulo (FEUSP). 


\begin{abstract}
The purpose of this article is to discuss teacher training in order to work with children based on the analysis of internship reports. We assume, as a premise, that writing about professional practices is more than a simple means of documentation or proof of activities; rather, it is a moment of reflection and analyses of the practice which can result in the production of knowledge. We analyzed ten internship reports in order to verify how undergraduates establish a relation between theory and practice. Considering the results, we can note that the main purpose of pedagogic thought is suppressed in the reports; in other words, the child appears little, and, when it is described, it is mainly as a faulty being, one who has not learned, has not developed, does not do or does not meet adult expectations. These data lead us to question what is happening in the current pedagogical training courses and the reasons why studies do not reflect on their practices.
\end{abstract}

Keywords: children, teacher training, literacy, internship reports

\title{
Introdução
}

$\mathrm{N}$

este trabalho nos propomos a analisar a imagem de criança/ infância em relatórios de estágio em alfabetização escritos como parte das atividades exigidas pelo projeto Ler e Escrever - toda força ao $1^{\circ} a n o^{2}$, posto em prática pela Secretaria Municipal de Educação da cidade de São Paulo, Brasil. O projeto consistia em colocar nas salas do primeiro ano do ensino fundamental I, ou seja, nas salas de alfabetização, dois "professores". As aspas no termo professores cabem na medida em que esse era o anúncio da propaganda política do projeto, mas não o que ocorria na prática. As salas teriam, na realidade, um professor regente (titular) e um estagiário como auxiliar. Os estagiários deveriam estar cursando a faculdade de Pedagogia ou Letras e, preferencialmente, não estar no último ano. Os graduandos participantes do projeto recebiam um pequeno auxílio financeiro e

2 Para saber mais acesse: http://www.alemdasletras.org.br/biblioteca/material_professor/ Ler_e_escrever_toda_forca_ao_1o_ano_vol_1.pdf e http://www.alemdasletras.org.br/biblioteca/material_professor/Ler_e_escrever_toda_forca_ao_1o_ano_vol_2.pdf 
tinham a obrigação de entregar relatórios mensais, além de participar de reuniões de formação regularmente.

É importante dizer que o presente trabalho faz parte de um projeto maior, o qual objetiva discutir o papel da escrita na formação de professores ${ }^{3}$. O projeto considera "que escrever sobre as práticas, para o professor em formação, não consiste apenas em uma forma de documentar ou comprovar suas atividades, mas é um trabalho do qual pode resultar a produção de conhecimento". Assim sendo, as reflexões aqui lançadas visam fomentar a discussão de modo a refletir se e como alunos da graduação, ao realizar estágios de pesquisa, estabelecem relação entre teoria e prática. Entendemos que, durante a formação inicial, as construções teóricas dos alunos estão em plena ebulição e ao associá-las à prática - na observação e ação proporcionada pelo estágio nas escolas -, os relatórios são mais do que simples cumprimento de uma tarefa burocrática, mas um recurso de reflexão do fazer-se professor e, consequentemente, produção de conhecimento.

Entendemos que o estágio é um momento ímpar na formação, pois somente durante sua vivência o futuro professor tem a possibilidade de observar e refletir a respeito da atuação do outro e, então, estabelecer objetivos e estratégias para atuar no cotidiano escolar em que está auxiliando. Dessa maneira, ele poderá refletir sobre sua prática a partir de elementos concretos e palpáveis - não só teóricos -, analisando-a e, assumindo para si próprio um posicionamento sobre a prática escolar, terá motivos concretos para ser a favor ou contra determinadas posturas, sejam elas do professor titular ou não.

Partindo dessa premissa, consideramos que os relatórios de estágio são a materialidade de onde ocorrerá a intersecção acima descrita. Acreditamos que o momento da escrita do relatório de estágio é aquele em que haverá a reflexão da prática ligada à teoria, por isso, ao analisarmos os relatórios entregues, podemos ter indícios de como está se dando a formação do futuro professor. Nesse sentido concordamos com Barzotto e Puh (2015) quando afirmam que,

ao descrever os modos como o aluno apresenta os dados e esboça suas análises, se tornarão mais palpáveis as condições de escrita

3 A escrita sobre as práticas de ensino em licenciaturas do Brasil, da Costa Rica e de Honduras: registro, análise e produção de conhecimento; projeto de pesquisa inserido na Chamada Universal MCTI/CNPq nº 14/2014. 
que os processos de formação estão proporcionando aos professores e o grau de domínio dos conhecimentos específicos de seu curso. Referimo-nos aos conhecimentos aprendidos em disciplinas anteriores à formação pedagógica, em disciplinas relacionadas à prática de ensino de língua portuguesa, bem como aqueles recolhidos na prática do estágio. (Barzotto \& Puh, 2015, p. 93)

Embora os autores tratem da formação do professor de Língua Portuguesa e não da do Pedagogo, entendemos que, sendo nosso objeto de análise o mesmo - relatórios de estágio -, esses preceitos são igualmente válidos, ou seja, procuramos verificar se é possível encontrar repercussões dos conteúdos específicos do curso de origem dos estagiários, diferindo somente, no trabalho aqui proposto, em que buscamos por aspectos mais especificamente relacionados à criança.

Os autores ainda propõem um perfil profissional que deva ser manifestado no texto escrito quando consideramos a leitura e a escrita como produção de conhecimento. As características esperadas desse perfil são: "1) escrever de acordo com as regras da língua padrão escrita; 2) demonstrar domínio e mobilização pertinente aos conhecimentos aprendidos durante a formação; 3 ) fazer do texto uma demonstração de compromisso em produzir avanços, o conhecimento". Estamos assumindo que os relatórios de estágio são produção de conhecimento no sentido de que há dois tipos de leituras implícitas (a de mundo, na observação da sala de aula; e a dos autores estudados durante a graduação) e dessa maneira esperamos encontrar "o domínio e mobilização dos conhecimentos aprendidos" ao longo da graduação (Barzotto \& Puh, 2015). Esperamos, também, poder observar de que maneira os autores presentes no curso de origem e suas teorias são utilizados para aprofundar as reflexões geradas pelas observações em sala de aula. Por fim, conseguirmos perceber o "compromisso" dos estagiários "em produzir avanços" já que estão no movimento de verificar se a teoria é aplicável na prática.

O texto aqui apresentado está dividido em quatro seções: na primeira, há uma descrição do corpus e a delimitação do mesmo para análise; na segunda, discute-se a relevância da atual formação de professores no momento da prática pedagógica; na terceira, levantamos a discussão a respeito do olhar dos futuros professores aqui analisados 
sobre seu propósito principal de trabalho - as crianças -; por fim, fazemos algumas considerações finais sobre os aspectos analisados.

\section{Delimitação e descrição do corpus}

O projeto Ler e Escrever - toda força ao $1^{\circ}$ ano acontece na cidade de São Paulo, Brasil, desde 2006, tendo sido inicialmente um projeto da Secretaria Municipal de São Paulo e posteriormente ampliado para o Estado de São Paulo. É um projeto realizado a partir de convênios entre universidades (públicas e privadas) e as Secretarias de Educação ${ }^{4}$. A Universidade de São Paulo integrou o projeto de 2006 a 2010, sendo que nesse período os estagiários participantes entregaram um total de 424 relatórios ${ }^{5}$, descrevendo suas atividades em cerca de 60 escolas municipais. O corpus aqui analisado é um recorte desse conjunto de dados maior. Composto de dez relatórios de estágio de quatro alunas diferentes, são todos do ano de 2006 e foram escolhidos por comporem o maior conjunto de relatórios referentes a uma mesma escola. Tal delimitação nos foi importante para que o contexto social - sendo o mesmo nos relatórios analisados - não fosse um fator relevante no julgamento, por parte dos estagiários, das práticas pedagógicas. Ou seja, ao limitar a análise dos relatórios ao mesmo contexto socioeconômico queríamos excluir a possibilidade de julgamentos valorativos relacionados à aprendizagem associados à diferentes estratos sociais. Por isso, esse foi um critério de escolha decisivo, uma vez que, fundamentalmente, desejávamos verificar em que medida as formações recebidas pelos estagiários - tanto no curso de origem, como nas reuniões de formação para participação do projeto - reverberavam na forma de observar e analisar a realidade que se colocava diante deles.

Os relatórios foram produzidos nos meses de março, abril, agosto, setembro e outubro - tempo de realização do projeto naquele ano -, e somaram um total de 138 páginas da observação de quatro salas de aula ( $1^{\text {os }}$ anos $\mathrm{A}, \mathrm{B}, \mathrm{C}$ e $\left.\mathrm{E}\right)$. Vale dizer que duas das quatro

4 A educação brasileira está dividida da seguinte forma: Educação Infantil (de zero a cinco anos) - tanto na rede municipal como na privada; Ensino Fundamental (dos seis aos 14 anos) redes municipais, estaduais e privadas; Ensino Médio (dos 15 aos 17 anos) - redes municipais, estaduais, federais e privadas; e Ensino Superior - estaduais, federais e privadas.

5 Dentre as responsabilidades dos estagiários estava a entrega mensal de relatórios, os quais deveriam descrever as atividades desempenhadas, assim como fazer reflexões sobre o processo de ensino-aprendizagem. Nas formações que recebiam na universidade, eram instruídos a fazerem um diário de campo para auxiliar na escrita dos relatórios, de maneira que estes fossem o mais completos e reflexivos possível. 
estagiárias ao longo do ano de 2006 entregaram quatro relatórios; a terceira estagiária, somente os dos meses de setembro e outubro e a última, apenas o do mês de agosto. Como somente temos os relatórios como fonte de análise, não é possível assegurar se esses foram os meses de permanência das estagiárias no programa, ou se por algum motivo outros relatórios não foram devidamente entregues.

Como nos relatórios não havia a especificação do curso de graduação das estagiárias, e por considerarmos esse um dado relevante, fizemos uma breve pesquisa na internet colocando o nome completo das estagiárias para obter tal dado. Isso nos era importante porque, $a$ priori, a maneira como a criança é vista e entendida, assim como o olhar para o processo de aquisição da escrita, deveriam ser distintos entre alguém formado para lidar diretamente com a infância (proveniente do curso de Pedagogia) e alguém formado para ter como objeto de trabalho a língua portuguesa (proveniente do curso de Letras). Na pesquisa descobrimos que as quatro estagiárias eram da Pedagogia e nenhuma do curso de Letras. Para a seleção do corpus, foram lidos diversos relatórios pertencentes ao projeto, e chamou-nos a atenção o fato de a escrita dos relatórios utilizados aqui para análise não demostrarem essa diferença na formação, fato que nos leva a pensar sobre como está se dando a formação inicial daqueles que estão sendo formados para trabalhar diretamente com a infância e quais são os reflexos na formação de nossas crianças. Como esta reflexão não é o foco do presente trabalho, no próximo tópico faremos um levantamento de questões.

Outro dado importante diz respeito às referências bibliográficas utilizadas nos relatórios. No recorte analisado, foram citados quatro autores - Emilia Ferreiro, Miriam Lemle, Marieta Lúcia M. Nicolau e Paulo Freire - e dois documentos oficiais, Parâmetros Curriculares Nacionais (PCN) e os livros guia do professor do projeto (TOF). Entre essas referências, Paulo Freire não foi citado de forma relacionada a nenhuma de suas obras, somente seu pensamento de maneira generalizada, e dois relatórios não possuíam qualquer referência bibliográfica. Além disso, importa dizer que, de maneira geral, a escrita dos relatórios tem diversos tipos de problemas relacionados ao uso da "língua padrão" e optamos por mantê-los assim na transcrição dos dados aqui analisados.

Esperava-se que nos relatórios aqui analisados houvesse a localização e descrição da Unidade Escolar logo no início; mas tal regra somente é seguida por uma das alunas. Desta forma, as informações 
que temos é que está localizada na periferia da zona oeste de São Paulo, atende principalmente a duas comunidades próximas e se localiza entre uma Escola Municipal de Ensino Infantil (EMEI) e um posto de saúde. Sobre a estrutura, que possui dois prédios: um com cinco salas, sala de leitura, sala de informática e uma pequena horta e o outro prédio com três andares.

Isso posto, seguimos então para a análise dos relatórios propriamente dita.

\section{Entre o ver e o refletir, a formação esquecida}

Neste item nos importa discutir como a formação recebida no âmbito universitário revela-se na escrita dos relatórios. Ou seja, considerando-se que a escrita dos relatórios se realizou por estudantes de graduação, estamos tomando como premissa que as teorias estão bastante afloradas e, assim, devam sem embasadoras de reflexões vivenciadas no cotidiano escolar.

Contudo, ao ler os relatórios de estágio, há um primeiro dado que nos chamou bastante atenção com relação às crianças: elas aparecem essencialmente no trabalho em sala de aula. É como se não existisse interação, ou elas próprias inexistissem, fora daquele espaço.

Nos dez relatórios analisados, somente três vezes é relatada alguma atividade com elas fora da sala de aula, mais especificamente em uma visita ao Instituto Butantã e aos museus a ele ligados (aparece em dois relatórios) e uma atividade realizada na quadra da escola. Contudo, não há nenhuma descrição de suas interações ou aprendizagens, nem uma reflexão do aproveitamento pedagógico da experiência para o desenvolvimento cognitivo ou social da criança, ainda fosse que focado apenas na aquisição da escrita.

O que encontramos nesses relatos são descrições simples da atividade realizada, como, por exemplo, em:

\section{Exemplo 1}

“(...) começamos a descer com os alunos para a quadra para que pudessem realizar atividades físicas como futebol e a brincadeira de corre cutia, (...) brincamos de jogo da memória e começaremos a pintar com guache".

Pode-se observar que nesse trecho o foco da descrição é o relato da atividade e não a criança. Esta está completamente apagada da 
descrição, tanto que somente há uma menção a elas, a palavra "alunos", mas esta serve somente como adjunto a palavra "descer", não sendo nem o sujeito do verbo, muito menos o foco semântico da oração. Se a frase tivesse sido escrita, por exemplo, "Os alunos desceram conosco para a quadra", ela colocaria o aluno como centro do processo, pois ele seria o sujeito da ação e não os adultos (professora e estagiária), tal qual foi escrita. Além disso, a descrição desse trecho nos remete a escola somente pela utilização do termo "alunos", mas, se o retirarmos, poderíamos utilizá-lo para descrição de qualquer outra situação no mundo, não trazendo nenhuma informação relevante do processo de ensino-aprendizagem desenvolvido no ambiente escolar.

A estagiária não discute, por exemplo, a reação das crianças na atividade, o relacionamento entre elas, a interação com as professoras, ou ainda como alguma atividade desenvolvida em sala de aula em que a escrita estivesse envolvida poderia ser vista nas brincadeiras. Além disso, os questionamentos que podem ser feitos são: será que a criança com dificuldades no desenvolvimento da escrita tem alguma dificuldade nas brincadeiras descritas? Ou ainda o inverso: as crianças que se saem muito bem nas atividades em sala de aula também desempenham com maestria atividades físicas e motoras? Esperávamos encontrar aqui reflexões por aparte das estagiárias sobre isso, uma vez a formação em Pedagogia propicia o conhecimento sobre as diferentes fases do desenvolvimento infantil - seja cognitivo, seja de escrita - e seus comportamentos. Vários são os autores que tratam sobre o assunto, como Ferreiro, Teberosky, Piaget, Vigotsky, entre outros, que fazem parte da bibliografia básica do curso.

Com relação ao trabalho em sala de aula, surge outro dado relevante: somente há descrições sobre a aquisição (ou não) da escrita.

Se levarmos em conta que o projeto Ler e Escrever - toda força ao $1^{\circ}$ ano tem como foco a aquisição da linguagem escrita, diríamos que os relatos são pertinentes. Porém, quando pensamos que o objeto de análise das estagiárias são as crianças e o processo de aprendizagem da leitura e da escrita por crianças, é de se esperar que muitas outras coisas relacionadas ao universo infantil apareçam para verificar essa aprendizagem. Principalmente se levarmos em conta que, como já foi discutido anteriormente, todas as estagiárias provinham do curso de 
Pedagogia e imaginávamos que, com a extinção dos cursos de magistério ${ }^{6}$, houvesse maior preparo para a análise da criança em sua formação e desenvolvimento.

Mesmo quando levamos em conta os relatos sobre a aquisição da escrita, saltam aos olhos dois aspectos: o primeiro com relação ao conhecimento da área e o segundo acerca da concepção de criança intrínseca às descrições.

Somente uma das quatro estagiárias demostra conhecimento sobre aquisição da escrita por crianças. Essa aluna estava cursando o segundo ano e nos quatro relatórios realizados por ela há citações de Emilia Ferreiro para embasar os dados levantados e constantes reflexões procurando conciliar teoria e prática. É o que podemos ver nos exemplos abaixo:

\section{Exemplo 2}

2.1 (...) no relatório desse mês pretendo analisar especificamente o progresso de quatro alunos da minha sala em relação à aquisição da língua escrita. (...) Observando as sondagens que eles fizeram ao longo do primeiro semestre e no começo do segundo, foi possível visualizar as fases que, geralmente, as crianças passam quando estão sendo alfabetizadas, segundo a autora Emília Ferreiro. Fases estas que mostram como as crianças em processo de alfabetização são ativas na construção de seus conhecimentos formulando problemas e interpretações.

2.2 (...) O que me intriga é que ele coloca a vogal para representar a sílaba oral ele coloca a consoante para escrevê-la, então de certa forma, o Bruno entendeu que as vogais atribuem som para as consoantes, só que apesar disso, ele ainda não assimilou que é necessário as duas letras juntas para compor a sílaba.

O Exemplo 2 são dados produzidos pela mesma estagiária em dois relatórios distintos. Podemos observar que embora exista um esforço da estagiária em relacionar o conhecimento adquirido com a prática que está vivenciando (Exemplo 2.1), ela acaba por reforçar a falta de uma das crianças por não ter adquirido a leitura (Exemplo 2.2). Embora ela utilize a expressão "o que me intriga" - que nos levaria a pensar que ela está refletindo sobre o processo de aprendizagem da criança e, portanto,

6 Essa questão está sendo discutida em minha dissertação de mestrado, "Do Magistério à Pedagogia: mudanças na formação de professores". 
fazendo uma ponte com a teoria que ela própria cita - é possível observar que ela não assimilou realmente a teoria estudada, não se dando conta de que a produção do aluno Bruno faz parte do processo de aquisição da escrita tal como descrito pela autora citada no relatório.

Em contrapartida, a estagiária que estava no penúltimo ano do curso revela: "trabalhei com diversas atividades, muitas intuitivamente, já que meus conhecimentos com alfabetização no começo não eram muitos"; contudo em nenhum dos relatórios apresentados ela demonstra o conhecimento adquirido sobre o assunto.

Há de se considerar a importância do estágio na formação do professor, principalmente, quando é uma oportunidade como a do projeto aqui discutido em que o estagiário não se coloca somente na posição de pesquisador-observador, mas de um ator do fazer pedagógico participando do cotidiano escolar ativamente e, a partir da experiência, pode refletir sobre a teoria. Entretanto, a questão aqui levantada é com relação à formação teórica adquirida pelas alunas-estagiárias ao longo do curso de graduação. As perguntas que ficam são: será que a universidade está formando professores realmente habilitados para a realidade do cotidiano escolar? Por que os estagiários dissociam a teoria da prática em seus relatórios? O que falta: conhecimento teórico, reflexão ou espaços para a associação de ambos? Embora o foco deste trabalho não seja responder a essas perguntas, acreditamos ser importante levantá-las para suscitarmos mais discussões sobre o tema.

Outro tipo de descrição comum nos relatórios contém avaliações subjetivas vagas, como, por exemplo, "divertida e sem maiores problemas com a visitação", "interessante e enriquecedor para as crianças" - sem, contudo, explicitar-se o que significa ser "enriquecedor", "divertido" ou "sem problemas". Novamente inúmeras elucubrações podem ser feitas: foi enriquecedor porque as crianças tiveram contato com algo que nunca tinham tido?; ou porque puderam praticar a leitura e escrita em outro ambiente que não a sala de aula?; ou porque interagiram intensamente com o meio e entre si? Enfim, essas, entre muitas outras perguntas, ficam em aberto, já que não há no relatório nenhuma outra análise sobre os fatos.

Somado às descrições subjetivas, o tom pejorativo, reforçando a falta daquilo que a criança ainda não é, não desenvolveu ou não tem, como já citamos anteriormente, ocorre com certa frequência nos relatórios. É o que podemos ver nos exemplos abaixo: 


\section{Exemplo 3}

"mesmo as crianças não lendo as explicações escritas nas exposições dos museus, creio que foi uma experiência nova para os alunos",

\section{Exemplo 4}

"com essa atividade é possível perceber que alguns alunos que consideramos alfabéticos não consegue entender o que lêem, cada palavra lida em uma frase, por exemplo, fica solta no entendimento não há encadeamento, conexões entre elas".

A escolha das palavras para relatar nos diz muito da forma como as observadoras veem o processo de aprendizagem. A palavra "mesmo" e as expressões "não consegue", "não há", por exemplo, levam o leitor a fixar naquilo que não é, na ausência que, no caso da alfabetização, é o conhecimento e domínio da leitura e escrita. Tal fato chama a atenção, uma vez que se trata de alunas que estudam o desenvolvimento infantil, como dito anteriormente, e deveriam conseguir ver esses processos de forma diferenciada, ou seja, na perspectiva daquilo que a criança já é capaz de realizar. Muitos são os autores estudados nos cursos de Pedagogia que tratam do assunto.

Autores como Montessori, Pestalozzi, Comenius e Rousseau trazem a perspectiva das potencialidades das crianças em seus diversos âmbitos de aprendizado. Piaget e Vygotsky, por exemplo, discorrem sobre o desenvolvimento cognitivo infantil; além de Ferreiro e Teberosky que trazem à tona conhecimentos sobre o processo de aquisição da linguagem escrita. Todos esses autores, para exemplificar somente alguns, fazem parte da bibliografia básica do curso de Pedagogia e, com certeza, foram estudados pelas estagiarias em questão. Chama-nos a atenção o fato de, na grande maioria dos relatórios analisados, não haver evidências de um conhecimento adquirido pelo estudo dos autores acima mencionados, por exemplo. E aqui não estamos nos referindo a simples citações desses autores ou de trechos de suas obras; muito pelo contrário, estamos nos referindo ao fato de que diante da leitura dos relatórios não é possível observar um olhar mais atento, por parte das graduandas, para o desenvolvimento das crianças que têm diante de si, olhar esse que as diferenciaria (as graduandas) de qualquer outra pessoa que não tenha tido a mesma formação que elas. 
Tal fato nos faz reiterar a questão: com o fim do magistério e a obrigatoriedade do curso superior em Pedagogia, o que de fato contribuiu para a melhora na formação desse profissional?

\section{Entre o ver e o refletir, a criança desaparecida}

Finalmente, a maneira como a criança é vista e entendida também nos chama a atenção.

Nos dez relatórios o ser infantil aparece ressaltado em suas faltas, naquilo que ainda não possui ou não se adequou, no que precisa alcançar, em sua defasagem ao esperado pelo mundo adulto. Ou seja, a criança é vista como alguém que um dia será e não pelo que já é.

As etapas de desenvolvimento da aquisição linguística proposta por Ferreiro são utilizadas pelas estagiárias como instrumento para dar visibilidade ao que a criança não é capaz de realizar - atitude que por si só já demonstra não compreensão da teoria. Falas como "os alunos tem dificuldade em fazer leitura de imagem", "alguns alunos não progrediram quase nada", "ele não tem vontade de aprender", "eles não conseguem compreender o que leem" são comuns e não contêm uma análise mais aprofundada do porquê ocorrem - será por que é normal para a idade?; ou por que o ambiente e a forma de ensinar não são interessantes, ou suficientes?; ou ainda, por que foram arrancados da ludicidade ${ }^{7}$ bruscamente e resistem ao que lhes está sendo imposto?

Com relação à última pergunta, cabe analisar como a ludicidade (entendida como ociosidade no ensino fundamental) é vista de uma forma negativa pelas futuras professoras. $\mathrm{O}$ ritmo diferenciado de produção e realização das atividades normalmente incomoda, pois as crianças que concluem mais rapidamente começam a "fazer bagunça"; portanto, é necessário mantê-las ocupadas.

7 A justificativa do governo brasileiro para a ampliação do Ensino Fundamental para nove anos era que a medida garantiria a ampliação do direito à educação para as crianças de 6 anos de idade, em especial as pobres e excluídas do sistema educacional. Na proposta inicial o primeiro ano deveria ser um momento de transição entre a educação infantil e os anos vindouros do ensino fundamental. Todavia, como os professores são intensamente cobrados por alfabetizarem as crianças, a ludicidade, que deveria fazer parte do processo de transição, foi deixada de lado e as crianças permanecem a maior parte do tempo fechadas nas salas de aula fazendo atividades para o desenvolvimento da escrita e do raciocínio matemático. 


\section{Exemplo 5}

"pensando na não ociosidade entre o intervalo de uma atividade e outra, colocamos a disposição dos alunos pranchas de textos (...) esta foi uma forma encontrada para evitar o ócio entre uma atividade e outra".

A faixa etária dos alunos do primeiro ano do ensino fundamental I é de 6 e 7 anos. São crianças que, até o ano anterior, tinham um tempo diferente relacionado ao brincar e a visão de ludicidade. Esse também é um assunto que faz parte do curso de Pedagogia e, no entanto, parece-nos que somente pelo fato de as crianças terem entrado no ensino fundamental esse aspecto tão relevante da formação infantil é deixado de lado, posto em segundo plano como algo não tão relevante.

É sabido que há uma forte pressão para que os alunos sejam alfabetizados na idade considerada pelo governo como certa. Essa é, inclusive, uma das propagandas políticas utilizadas pelo governo (alfabetizar exatamente no primeiro ano do ensino fundamental I) e, por isso, até poderíamos esperar certo preenchimento de espaços pela professora regente de maneira a otimizar o tempo para alcançar a meta a ela imposta. Porém no dado apresentado acima, a estagiária se coloca como participante do processo - com o verbo colocamos - de pensar estratégias para que as crianças não ficassem sem atividade de leitura e escrita, sem considerar que elas podem adquiri-los em outras situações, inclusive, lúdicas. Mais uma vez, a formação recebida não vem à tona contribuindo para uma reflexão do processo e de todos nele envolvidos.

No outro extremo, o aluno que não termina juntamente com os outros é visto como problemático, quando não com algum tipo de doença, como podemos ver no trecho a seguir:

\section{Exemplo 6}

"Tiago tem sete anos. Desde a primeira ida a escola foi apresentado como alunos com necessidades especiais por ter tido meningite quando pequeno e haver a suposição de que este evento trouxe algum comprometimento intelectual. Tem fala estruturada, bons argumentos, mas um tempo de atenção bastante curto. Durante uma explicação ele sempre encontra algo que o distraia e com o qual possa brincar (a blusa, o tênis o cabelo dos outros). Há dias em que passa a manhã ocupando-se com o lápis e quando o olho tenho a certeza de que está fazendo o que é realmente mais interessante e divertido para ele naquele momento, 
tal sua satisfação. Intervimos pedindo para que ele se concentre, que escreva o que sabe (ele é silábico)".

O trecho acima é bastante instigante e nos traz uma série de possíveis análises.

O primeiro dado relevante é que o aluno é apresentado como tendo um comprometimento intelectual resultante de uma meningite, mas não há nenhuma descrição de atividade que comprove essa deficiência. Muito pelo contrário. O único "problema" apresentado na descrição feita pela estagiária é o fato dele ser distraído, mas ao mesmo tempo em que ela coloca isso como um problema, faz a observação de que Tiago o faz porque se satisfaz mais com outras coisas e não com o que estão tentando lhe ensinar. A estagiária poderia ter aproveitado e registrado o que a professora estava ensinando e de que forma o fazia para que o aluno achasse mais interessante brincar com o lápis. Podemos utilizar esse momento como reflexão sobre o fato que discutimos anteriormente, de as crianças serem muito pequenas e serem abruptamente retiradas da ludicidade para serem tratadas como adolescentes, ou mesmo adultos, que teoricamente deveriam ter maior atenção àquilo que está sendo dito pelo professor.

Vale ressaltar que esse dado foi colhido do relatório entregue no mês de agosto e o fato de o menino ser silábico não é absurdamente fora dos parâmetros colocados com relação à aquisição da leitura e escrita para as crianças do primeiro ano. Tal fato reforça ainda mais o valor negativo dado pela instituição e pela estagiária ao afirmarem que Tiago possui comprometimento intelectual, quando na verdade o que o dado revela é exatamente o contrário: Tiago é somente uma criança, como outra qualquer, que gosta de brincar e se distrai quando o que estão lhe apresentando não lhe é interessante, ou ainda que pode estar resistindo ao ambiente que lhe é imposto.

Com relação à introdução das crianças ao ambiente e cotidiano escolar, encontramos também algumas descrições, tal como segue:

\section{Exemplo 7}

(...) foi possível observar um progresso por parte dos alunos, principalmente, no que se refere às adaptações das crianças às práticas e hábitos escolares. Afirmo isso, porque alguns professores contaram que, no início do ano letivo, muitos alunos não sabiam se comportar em uma sala de aula, não sabiam pegar em um lápis direito e nem 
sabiam qual era a forma correta de escrever em um caderno. No entanto, atualmente, os alunos já se habituaram ao cotidiano escolar, portanto, já aprenderam os códigos da cultura escolar. Assim sendo, já sabem segurar corretamente em um lápis, aprenderam que se escreve da esquerda para a direita, também já se acostumaram a pegar o caderno de classe quando há exercícios para se copiar da lousa e, por último, quando a professora pede para eles colocarem a agenda na sua mesa, eles atendem-na automaticamente.

Além de, novamente, a criança e seu universo não aparecerem, é reforçada uma visão de que "aluno bom é aquele que melhor se adaptou". Tal construção se dá por meio das palavras em negrito no texto. Essa é uma concepção de escola centrada no adulto e nas imagens estereotipadas de que a criança deva se "comportar" como um adulto em miniatura.

O controle e a disciplinarização do corpo foram a maneira que o homem moderno encontrou para controlar exércitos, por exemplo, através de uma coerção ininterrupta, de controle absoluto de atividades e esquadrinhamento do tempo, espaço e movimentos (Foucault, 1999). A mesma lógica foi transferida para o ambiente escolar: tempos de início e término de aulas (geralmente 50 minutos), carteiras enfileiradas, pouca possibilidade de movimentação no espaço, exigência de atenção constante sem oportunidade de ociosidade e atividades corporais devidamente orientadas. Aqueles que não se "adaptam", "habituam" ou "comportam" dentro do desejado são considerados maus alunos ou, ainda pior, são taxados de possuir alguma deficiência e encaminhados a medicalização, a maneira com a qual a escola do século XXI encontrou de continuar a controlar os corpos das crianças 8 .

Era de esperar que a estagiária fizesse alguma reflexão sobre o assunto. Contudo, ao invés disso ela adere ao discurso escolar reproduzindo-o sem, de fato, olhar para a criança e ponderar sobre o sistema em que ambas estão inseridas. Assim, nem a criança, nem a estagiária aparecem como sujeitos ativos do processo de ensino-aprendizagem, uma vez que cabe à primeira "adequar-se" e "atender automaticamente" às ordens da professora e, à segunda, imitar comportamentos estereotipados do bom professor.

8 Sobre esse assunto ler a dissertação de mestrado "Aquilo pelo que se luta nos discursos sobre TDAH dirigidos a professores e pais" (Galhardo, 2014). 
Ainda sobre o estereótipo do bom aluno a partir a perspectiva adultocêntrica, encontramos o seguinte dado:

\section{Exemplo 8}

A Jheinfer já é o oposto do Vitor, pois ela é uma aluna faltosa e mesmo quando vem para a escola, nãos se esforça para fazer as lições, na verdade, ela não tem vontade em fazer os exercícios, quando falo para ela que só assim ela aprenderá a ler e a escrever ela me responde que não quer aprender. Ela gosta de brincar, arrumar-se, colecionar figurinhas, mas estudar não lhe atraí. Creio que, no caso dela, o que ocorre é falta de maturidade, eu posso perceber isso comparando-a com os outros alunos que vem para escola conscientes que estão lá para aprender e estudar. Essa questão de maturidade é essencial se pensarmos no cotidiano escolar que exige disciplina por parte do aluno, sabendo que há hora para estudar e para brincar e conversar. A Jhenifer é uma criança que não deveria estar na $1^{\text {a }}$ série e sim na pré-escola, onde as atividades lúdicas são mais presentes que no ciclo I. com a nova lei da entrada das crianças com 6 anos no ensino fundamental, creio que o problema da imaturidade dos alunos aparecerão cada vez mais e, por isso pode desencadear um histórico de fracassos para a criança.

Podemos observar nesse trecho que a noção de infância é vista, pela estagiária, como algo negativo: a aluna "gosta de brincar", não é "consciente" do seu papel na escola e é imatura, por isso não deveria estar ali. Há uma supervalorização da disciplinarização e daqueles que, aos seis anos de idade, já se adequaram ao "cotidiano escolar" e sabem "que há hora para estudar e para brincar e conversar"; em contrapartida, não há qualquer discussão sobre a pedagogia ou metodologia adotadas pela professora - ou pela escola enquanto instituição -, ou ainda sobre os tempos e espaços propiciados para a criança se expressar, brincar e ir se encantando pelo processo de aprendizagem dos conteúdos escolares.

A estagiária atribui, ainda, o fracasso escolar às crianças e à sua imaturidade para estar na escola, sem ao menos fazer qualquer reflexão sobre a política pública que estava entrando em vigor naquele momento (a "nova lei" citada no dado). Em 6 de fevereiro de 2006, foi promulgada da Lei Federal $n^{\circ} 11.274$ que obrigava a entrada de crianças de seis anos no Ensino Fundamental I, alterando, portanto, o tempo de permanência nesta etapa da escolarização, que passou de oito para nove anos. Na época em que entrou em vigor a citada lei, muito se discutiu sobre as 
questões da infância e o impacto causado na vida da criança que passaria a entrar mais cedo na escola. Embora tivesse havido por parte da Secretaria Municipal de Educação resistência em colocá-la em prática, passando a vigorar nas escolas municipais somente no último ano estipulado pelo Governo Federal como limite à implantação, a estagiária poderia levantar tal discussão e, a partir do dado empírico, discutir o real impacto na vida das crianças e, também, no ambiente escolar.

Por último vale analisar o silenciamento das crianças por parte das estagiárias. Foi proposto para elas que no último relatório fizessem entrevistas com as pessoas da escola. As duas estagiárias que entregaram esse relatório final entrevistaram os professores e coordenação, mas não as crianças. Uma das estagiárias chega a mencionar o pedido feito para esse trabalho: "Para o final do projeto Ler e Escrever foi pedido para que recolhêssemos depoimentos da coordenação, dos alunos e do professor sobre o nosso desempenho no projeto".

Embora na descrição da atividade estivesse que deveriam entrevistar os alunos, estas não foram realizadas. Não é possível afirmar categoricamente por que as estagiárias não entrevistaram um aluno sequer, mas, diante dos dados analisados até aqui, podemos levantar algumas hipóteses.

Primeiramente, poderíamos dizer que diante de uma visão educacional adultocêntrica os sujeitos mais importantes são os adultos, pois esses já são, diferentemente das crianças que, em formação, ainda vão ser. Assim, numa escala de importância dá-se voz àqueles que tem poder.

Uma segunda hipótese seria pensar que as estagiárias, talvez, tivessem considerado que as crianças não teriam algo de relevante para falar sobre o trabalho que elas desempenharam. Sobre isso, uma das estagiárias declara:

\section{Exemplo 9}

A respeito das crianças da minha sala eu não gravei depoimentos, pois pensei que seria mais interessante pedir para elas me escreverem algo ou mesmo desenharem, já que elas estão em processo de alfabetização e o projeto foi criando justamente, com o intuito de auxiliá-las nesse processo. Sendo assim, após informar aos alunos sobre a minha saída e tentar explicar o porquê, pedi para eles me escreverem ou desenharem algo. 
Nesse exemplo podemos observar duas características proeminentes de como a estagiária entende e enxerga as crianças: 1) como a criança está na escola para aprender a ler e a escrever ela deve expressar-se, prioritariamente, através da escrita como uma forma de demostrar seu aprendizado, e validar a presença da estagiária na sala de aula; 2) o pedido da estagiária para as crianças é completamente vago - "escreverem ou desenharem algo" - o que nos leva a pensar que a futura professora desconsidera que as crianças possam ter uma opinião sobre seu trabalho com elas. Ao pedir que façam "algo" ela ignora o direcionamento que the foi dado na universidade (o de entrevistar os envolvidos sobre seu desempenho no projeto), ao mesmo tempo em que, novamente, apaga a criança como sujeito do processo de ensino-aprendizagem e possuidor de opinião.

Assim sendo, os dados que aparecem com relação às crianças estratificam-se no campo emocional:

\section{Exemplo 10}

A despedida com as crianças foi muito calorosa, algumas choraram e todos os outros me abraçaram muito forte, manifestando sua tristeza com a minha saída.

Nesse momento, elas são citadas de forma positiva por meio de termos como "calorosas", "solidárias" etc., os quais demonstram "tristeza" com a partida da estagiária, o que no entendimento desta é sinônimo de um bom trabalho desenvolvido.

\section{Considerações finais}

A análise dos relatórios de estágios nos traz, principalmente, dois indícios relevantes sobre a formação do professor destinado a trabalhar com crianças.

O primeiro a se considerar é sobre a relação teoria e prática. Durante o curso de Pedagogia há uma gama de autores estudados que tratam desde o fazer pedagógico até o desenvolvimento infantil. O profissional formado nesse curso será um especialista da infância e, portanto, espera-se dele um olhar diferenciado a respeito da criança, seus conhecimentos e suas fases de desenvolvimento. Na contramão do esperado, os relatórios não apresentaram esse diferencial e nos impelem a levantar alguns questionamentos: 1) por que os estudantes de Pedagogia não conseguem associar as teorias estudadas no âmbito 
universitário às práticas do cotidiano escolar?; 2) que diferença há entre o profissional formado em Pedagogia e os de outras licenciaturas?; 3) houve diferença na formação do professor da infância com a extinção dos magistérios e a obrigatoriedade do ensino superior?

A segunda questão a ser considerada é a maneira como a criança é vista e entendida pelas estagiárias. Como pudemos observar, a criança como tal, com suas características próprias, seu universo, suas fases de desenvolvimento, está suprimida dos relatórios. O olhar do pedagogo para essas questões simplesmente não aparece e, por consequência, a criança também não.

O aluno não é descrito nos relatórios como o ente principal do âmbito escolar, ou o sujeito ativo ou, tampouco, como um ser humano em formação, mas tão somente como coadjuvante do processo, um sujeito passivo e repleto de faltas. Em um momento em que aparentemente a criança tem um espaço muito grande no meio social, como detentora de muitos direitos, por exemplo, há de se questionar por que as futuras professoras não os enxergam. Alguns questionamentos também podem ser levantados sobre isso: 1) será que o discurso em torno da criança, o qual diz que ela é supervalorizada na atual sociedade, não condiz com a realidade vivenciada?; 2) será que a infância é entendida, pelas futuras professoras, como uma fase em que o ser humano precisa ser moldado, assim como uma folha de papel em branco precisa ser escrita?; ou ainda 3 ) as estagiárias simplesmente reproduziram os discursos produzidos naquele ambiente sem se darem conta de que o faziam?

Enfim, como deixamos claro no início do tópico, acreditamos que essa discussão está longe de chegar ao final. Contudo, faz-se necessário refletirmos e a aprofundarmos para que possamos chegar as conclusões de onde estão os erros - se é que eles existem - e, então, propormos mudanças. 


\section{Referências}

Barzotto, V., Puh, M. (2015). O perfil e a atitude investigativa do profissional de

Letras diante do dado no relatório de estágio. In Riolfi, C. (Org.), Professor de

português: como se forma, trabalha e entende sua prática (pp. 91-111). São Paulo: Paulistana.

Foucault, M. (1999) Os corpos dóceis. In Vigiar e punir: nascimento da prisão (pp. 117-142). 20a edição. Vozes: Petrópolis.

Galhardo, N. D. (2015) Aquilo pelo que se luta nos discursos sobre TDAH dirigidos a professores e pais (dissertação de mestrado). Faculdade de Educação da Universidade de São Paulo (FEUSP), São Paulo, SP, Brasil. 